\title{
Surgical treatment for hypertrophic cardiomyopathy: a historical perspective
}

\author{
Dustin Hang, Anita Nguyen, Hartzell V. Schaff \\ Department of Cardiovascular Surgery, Mayo Clinic, Rochester, Minnesota \\ Correspondence to: Hartzell V. Schaff, MD. 200 1st Street SW, Rochester, MN 55905, USA. Email: schaff@mayo.edu.
}

\begin{abstract}
Our understanding of hypertrophic cardiomyopathy (HCM) as a disease entity has increased dramatically over the last half century. There has been a concerted effort by several surgical groups to develop operative techniques to relieve left ventricular outflow tract (LVOT) obstruction and alleviate symptoms. This paper traces the development of transaortic septal myectomy, the current gold standard therapy for relief of LVOT obstruction, in symptomatic patients refractory to medical treatment. In addition, we introduce newer methods for myectomy that have expanded the role of surgery in patients with various forms of HCM.
\end{abstract}

Keywords: Hypertrophic cardiomyopathy (HCM); septal myectomy; history

Submitted Feb 16, 2017. Accepted for publication Mar 29, 2017.

doi: 10.21037 /acs.2017.04.03

View this article at: http://dx.doi.org/10.21037/acs.2017.04.03

\section{Introduction}

During the latter half of the 20th century, our understanding of hypertrophic cardiomyopathy (HCM) has evolved substantially, perhaps most noticeably illustrated by the many variations in its nomenclature, ranging from functional aortic stenosis, to idiopathic hypertrophic subaortic stenosis, to hypertrophic obstructive cardiomyopathy, to $\operatorname{HCM}(1,2)$. The latter is now the preferred name to describe the wide spectrum and heterogeneity of the manifestations of this disease, as well as to emphasize the fact that left ventricular outflow tract (LVOT) obstruction, while common, is not a pathognomonic finding (3).

As our understanding of the pathophysiology of HCM progressed, surgical techniques were developed in an attempt to relieve LVOT obstruction and attendant symptoms. Today, the gold standard for obstructive HCM refractory to medical therapy is surgical septal myectomy $(4,5)$.

\section{Early development of surgical techniques}

The initial surgical efforts in the management of HCM were hampered by the lack of adequate and clear imaging of the ventricular morphology, as well as understanding of the underlying pathology. In 1957, Brock described cases of muscular subaortic stenosis characterized by severe left ventricular hypertrophy in the absence of any aortic valve pathology (6). He noticed the characteristic endocardial thickening that is the hallmark of apposition (contact lesion) between the anterior mitral leaflet and septum caused by systolic anterior motion (SAM), but he incorrectly concluded that the etiology of the muscular hypertrophy was likely due to systemic hypertension and, therefore, was not a surgical condition. A year later, Teare reported an autopsy series of eight young patients who died suddenly and were found to have "asymmetrical hypertrophy of the heart" (Figure 1) (7). Interestingly, in a footnote to the article, the author wrote that the 16-year-old brother of one of the patients in this series died suddenly and had the identical cardiac finding of septal hypertrophy. In this early era of open cardiac procedures, many surgeons were baffled when they saw no intraoperative evidence of aortic valve stenosis or subvalvular membrane in patients whose preoperative catheterization had indicated LVOT obstruction, and their frustration continued when they saw a persistent gradient after discontinuation of cardiopulmonary bypass (8).

Goodwin et al. were the first to describe surgical management targeted at the hypertrophied septum, which was performed by Cleland in London, UK, on November 26th, 1958 (2). The reported patient had classic signs and 


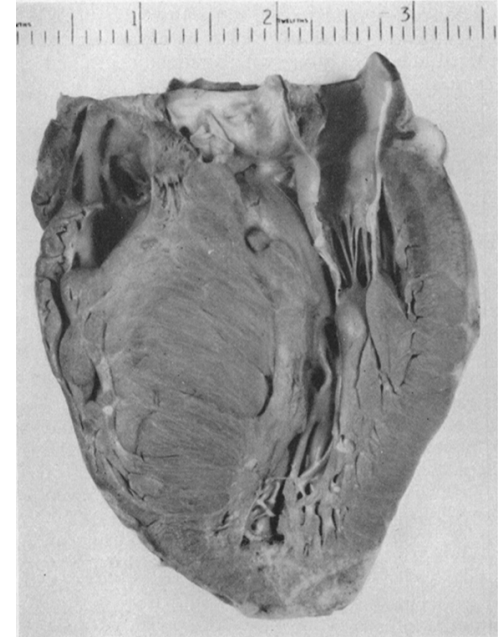

Figure 1 A pathologic specimen from a report by Dr. Robert Donald Teare at St. George's Hospital in London demonstrating asymmetrical hypertrophy of the left ventricle, most notably of the interventricular septum (7) (Copyrighted and used with permission of BMJ Publishing Group Ltd.).

symptoms of valvular aortic stenosis, including angina, dyspnea on exertion, and syncope, as well as a pressure gradient of $60 \mathrm{mmHg}$ between the left ventricle and the brachial artery. However, there was concern for a different underlying etiology due to an abnormal rapid upstroke of the arterial pulse and the absence of valve calcifications on chest radiography, and the presumed diagnosis was asymmetrical hypertrophy of the left ventricle. At operation, the aortic valve was normal, but obstruction of the LVOT due to "an enormously enlarged ventricular septum" was found on digital palpation of the subaortic area (2). Only a small amount of hypertrophied muscle was excised, and after an uneventful postoperative course, the patient experienced significant improvement in his symptoms. Cleland then described his surgical experience with six more patients who had an operation from 1960 to 1962 (9). In all patients, the approach was through the aorta with partial excision of hypertrophied/abnormal septal muscle. The mortality rate was high — two deaths out of seven patients—but nonetheless, four had marked improvement in their symptoms 2-4 years postoperatively. At the time, Cleland and his colleagues were unsure of the mechanism of the observed clinical improvement. In the majority of their patients, only limited excision of septal muscle was performed, but this seemed to produce satisfactory symptomatic relief.

At the same time as Cleland working in the UK, North

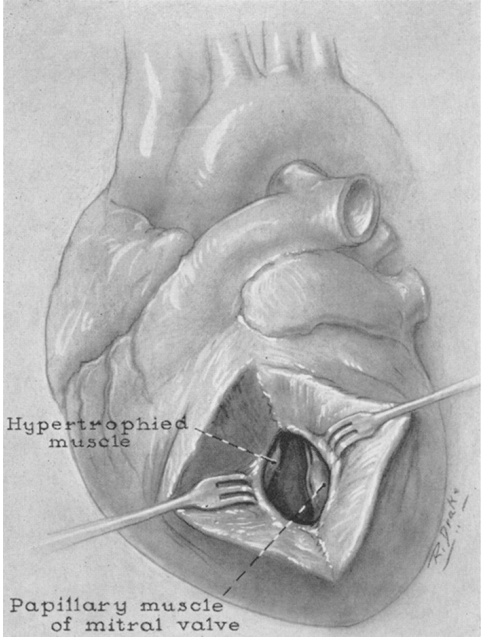

Figure 2 The transaortic and transventricular approach utilized by Drs. Kirklin and Ellis at the Mayo Clinic in the early 1960s to excise hypertrophied septum in the LVOT (10) (Copyrighted and used with permission of Wolters Kluwer Health, Inc.).

American surgeons had also begun to develop their operative techniques for muscular subaortic obstruction. In 1959 and 1960, Kirklin and Ellis of the Mayo Clinic operated on two patients using a combined transaortic and transventricular approach (Figure 2) (10). After instituting cardiopulmonary bypass and cross-clamping the aorta, a vertical aortotomy was made to allow the left index finger to pass through the aortic valve into the ventricle. The hypertrophic lesion and a suitable location in the left ventricular free wall (with regard to the coronary anatomy) for a ventriculotomy approximately $2.5 \mathrm{~cm}$ in length were identified. Excision by sharp dissection of the hypertrophic muscle would follow through the ventriculotomy, with the left index finger remaining on the aortic valve to avoid injury. After repair of the aortotomy and release of the cross clamp, the LVOT was palpated through the ventriculotomy with the heart beating to assess for adequate relief of obstruction (10). In both patients, the LVOT obstruction was almost completely relieved, and in one patient, full resolution of symptoms with resumption of strenuous activity 1 year postoperatively was noted. The subsequent Mayo Clinic experience was described by Frye et al. in 1965, where the transaortic and transventricular technique was used in 14 patients. Of the four patients who had postoperative hemodynamic studies, only one had a residual gradient greater than $20 \mathrm{mmHg}$; however, in all patients, the gradient rose to an average of $51 \mathrm{mmHg}$ after 
administration of isoproterenol. Nonetheless, 13 of the 14 patients experienced resolution of their preoperative symptoms, and there was only one postoperative death (11).

At the National Heart Institute in Bethesda, MD, Morrow et al. first described their surgical experience with HCM in 1960. At the time, symptoms of HCM were ascribed to a "sphincter-like contraction ring in the outflow tract" (12). The underlying physiology of SAM of the mitral apparatus responsible for dynamic obstruction in HCM had not yet been identified. Morrow's technique was aimed at relieving this "constrictive ring" using a subaortic ventriculomyotomy. He modeled his surgical approach after procedures relieving obstruction due to muscle spasm or hypertrophy, such as the Heller myotomy for achalasia (13). After a median sternotomy and institution of cardiopulmonary bypass, an oblique aortotomy was made and the aortic valve cusps were retracted to visualize the obstructive muscle mass in the outflow tract. From the apex to the aortic annulus, an incision over the most prominent portion of the muscle protruding into the LVOT was made, either with a conventional knife or malleable fingerknife. This initial incision cut through the endocardium and superficial muscle layer, and was deepened further by blunt dissection, or "splitting" of the deeper muscle, with the left index finger to a depth of $2-3 \mathrm{~cm}(8,12)$.

At Toronto General Hospital, surgical management of four patients was reported in 1963 (14). Their cardiac surgery group used a technique almost identical to Morrow's myotomy, again supporting the notion that the myotomy works in a similar fashion to the Heller myotomy in relieving the sphincter. Bigelow et al. continued to operate using this technique on 17 more patients, with relatively good postoperative outcomes $(15,16)$. The Toronto group would continue to support the ventriculomyotomy approach for many years $(17,18)$.

Meanwhile, Morrow continued to refine surgical treatment for HCM at the National Heart Institute. By 1964, he and his team had performed ventriculomyotomy in five patients, and in another five patients they combined the ventriculomyotomy with a partial resection of the hypertrophied muscle. In the latter patients, parallel superficial incisions were made over the most prominent portion of the muscle, separated by a distance of approximately $1 \mathrm{~cm}$; after manual splitting of both incisions, the resulting bar of tissue between the incisions was removed by rongeurs, resulting in excision of approximately 1 to 2.5 grams of tissue. Interestingly, Morrow commented that perhaps a resection was not necessary, but rather an

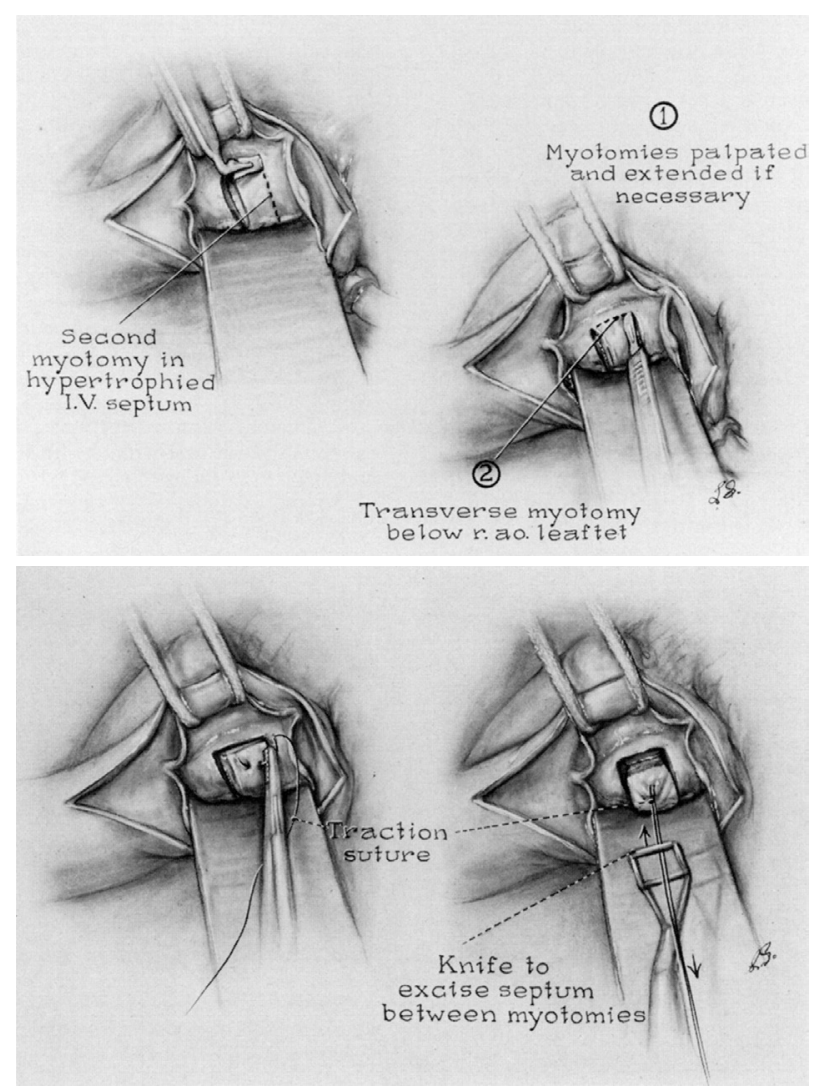

Figure 3 The traditional Morrow technique utilizing parallel incisions into the hypertrophied septum followed by excision of the resulting bar of septal muscle (20) (Copyrighted and used with permission of Wolters Kluwer Health, Inc.).

isolated ventriculomyotomy with no resection of muscle was adequate for relief of LVOT obstruction and its associated symptoms (8).

Despite his initial hesitation regarding the need for resection, Morrow continued to partially resect the hypertrophied subaortic muscle in an additional 15 patients, which he described in a series published in 1968 (19). By 1975, Morrow et al. had operated on a total of 83 patients, using the parallel incisions approach with small refinements to his technique (Figure 3) (20). Instead of using a malleable finger-knife to make the initial superficial myotomies, the two parallel incisions were now made with a No. 10 knife blade on an angled handle. The knife was inserted directly into the septum beneath the base of the right aortic coronary cusp and withdrawn in a sawing motion towards the ventricular lumen. These parallel incisions were then connected with a transverse myotomy, and the resulting bar of septal muscle 
was either excised with a rectangular knife or peeled off the septum with a rongeur. The result was a "rectangular channel about $1 \times 1.5 \mathrm{~cm}$ " and 4 or $5 \mathrm{~cm}$ in length originating from just below the aortic annulus towards the midventricle. Morrow put less emphasis on the length of resection, but rather focused on the depth of the incision, which was a function of the preoperative septal thickness $(20,21)$.

\section{Contribution of the mitral valve to obstruction}

The gradual recognition of SAM of the mitral leaflets in the pathophysiology of HCM is of great significance. Bjork et al. first noticed abnormal movement of the anterior mitral leaflet in 1961, but it would take another 20 years of angiographic and echocardiographic research before the simultaneous temporal relationship between SAMseptal contact and the development of the pressure gradient was proven, marking SAM-septal contact as a primary event in LVOT obstruction rather than a secondary occurrence (22-27). It became clear that SAM caused both the LVOT obstruction as well as the mitral regurgitation in HCM. With the contribution of the mitral valve to the pathophysiology of HCM confirmed, many believed that intervention on the mitral valve was necessary at the time of septal reduction. Indeed, Cooley and associates advocated mitral valve replacement to relieve outflow tract obstruction in patients with $\operatorname{HCM}(28,29)$, and while excision of the anterior leaflet corrects obstruction, it leaves the patient with the late hazards of a mitral valve prosthesis. Morrow, however, was a firm believer that intervention on a structurally normal mitral valve was rarely necessary in HCM, even those with hemodynamically important mitral valve regurgitation $(20,21)$.

\section{Introduction of the extended myectomy}

In 1994, Messmer introduced the concept of an extended septal myectomy for obstructive $\operatorname{HCM}(30,31)$. He identified the inherent disadvantage of the classic Morrow technique; i.e., inadequate resection of the distal septum due to suboptimal exposure. In Messmer's technique, retraction of the aortic valve cusps is achieved with stay sutures, and a sharp triple-hook retractor is inserted through the aortic valve and is hooked underneath the deepest part of the septal bulge, which is not visible to the operating surgeon. Tension on the retractor facilitates distal septal excision. Messmer described an initial resection of the hypertrophied septum in a similar fashion to Morrow's technique, making sure to angle the transverse incision towards the retractor. Importantly, additional resection is then carried out at the junction of the septum and the lateral left ventricular wall, as well as the junction of the septum and the posterior wall at the midventricular level.

Messmer did not believe that SAM of the mitral leaflets and the resulting mitral regurgitation were due to Venturi forces as previously described by Wigle et al. (32). Instead, he hypothesized that SAM and mitral insufficiency were due to excessive hypertrophy and malposition of the papillary muscles causing displacement of the mitral leaflets in systole. Therefore, he would inspect the mitral apparatus in each patient, and his extended myectomy would also include freeing any secondary attachments between the left ventricular wall and the papillary muscles as well as trimming any excess muscle (30).

\section{Evolution of septal myectomy at Mayo Clinic}

The current technique used at the Mayo Clinic (33) has been developed over the last three decades from experience in over 3,000 patients and differs from the classical Morrow technique and the aforementioned technique described by Messmer. For those patients with a predominantly subaortic LVOT gradient, a transaortic approach is still preferred. After a standard median sternotomy and before institution of cardiopulmonary bypass, a resting LV-to-aortic pressure gradient is calculated by simultaneously measuring the pressures at both the aorta near the inflow cannula and the left ventricle (34). A dynamic gradient is recorded by gently stimulating the heart to induce a premature ventricular contraction. After cross-clamp of the aorta and cardiac arrest with cold blood cardioplegia, a "hockeystick" oblique aortotomy is made, which begins cephalad to the right coronary sinus and continues rightward and inferiorly towards the base of the non-coronary sinus, resulting in an aortotomy that is lower than that used in a traditional aortic valve procedure. Adequate exposure of the subaortic area can be obtained by various means, including utilizing pericardial stitches only on the right side of the heart, stay sutures on the inferior aspect of the aortotomy, and a sponge-stick to depress the RV and rotate the left ventricle posteriorly. Finally, the surgical assistant will place a cardiotomy sucker through the aortic valve against the commissure between the left and non-coronary sinuses in order to remove blood from the operative field and displace the anterior mitral leaflet posteriorly.

After identifying the white fibrous tissue that demarcates 
A

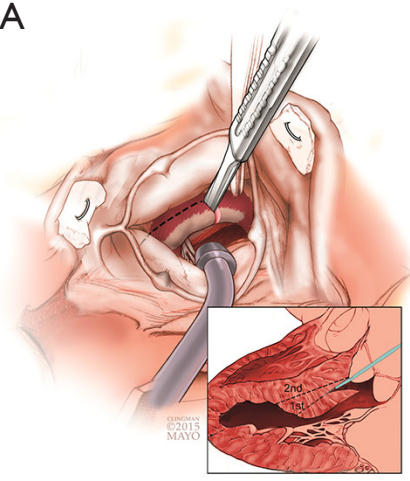

B

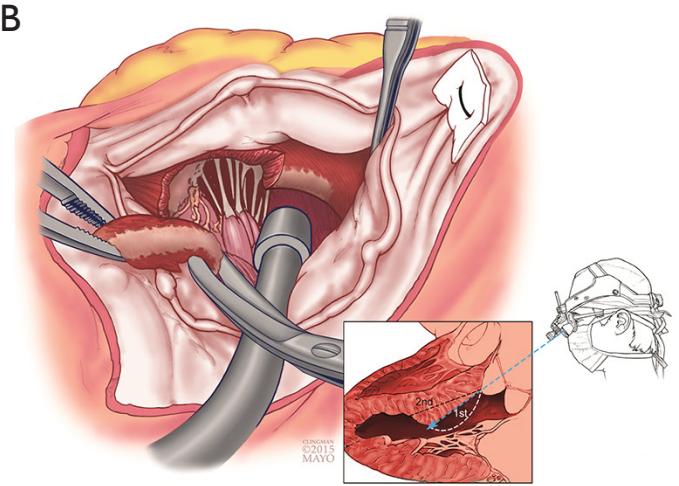

C

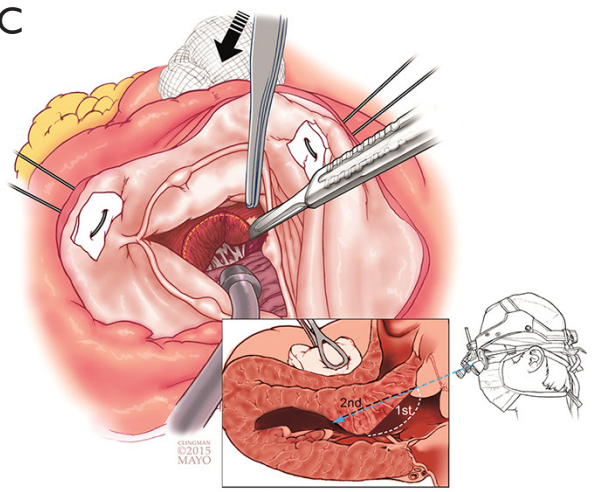

Figure 4 Operative steps of the current Mayo Clinic technique, demonstrating an initial excision of the hypertrophied septum at the point of mitral-septal contact (i.e., white fibrous scar) in Panels A and B, followed by extension of the excision towards the apex of the left ventricle after adequate exposure in Panel C (Copyrighted and used with permission of Mayo Foundation for Medical Education and Research).
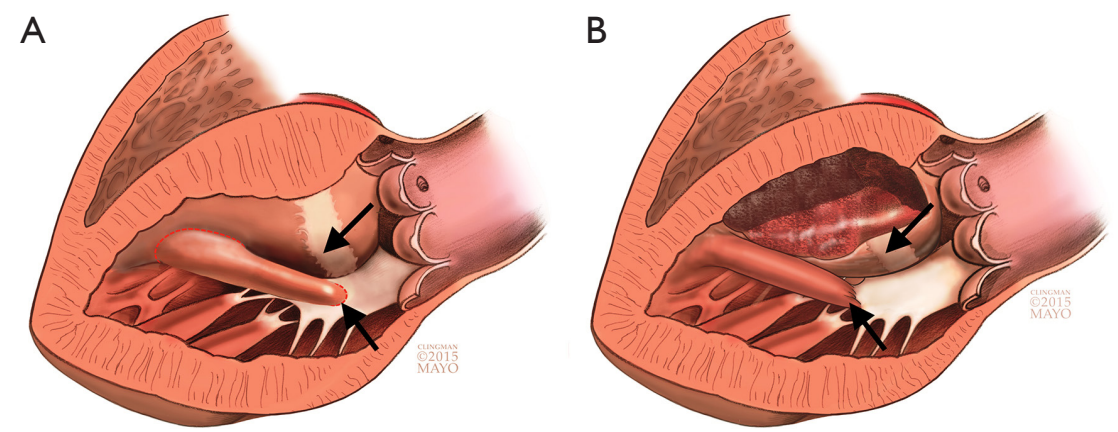

Figure 5 Panel A depicts an anomalous papillary muscle inserting directly into the body of the mitral leaflet, resulting in obstruction by contact between the papillary muscle and septum (black arrows). Panel B demonstrates a different configuration of an anomalous papillary muscle inserting into the leaflet edge, which does not result in contact between the papillary muscle and septum (Copyrighted and used with permission of Mayo Foundation for Medical Education and Research).

the location of septal-mitral contact from SAM, the surgeon then uses a No. 10 knife blade on a long handle to make an incision in the septum beginning just to the right of the nadir of the right aortic sinus. This incision is carried upward initially and then leftward toward the anterior leaflet of the mitral valve. To assess for the correct incisional depth, the width of the No. 10 blade is used as reference. Subsequently, the initial excision is deepened and further carried towards the apex of the LV to excise hypertrophied septum beyond the endocardial scar as well as any trabeculations. Depression of the RV at this time aids in exposure of the distal septum (Figure 4). Pituitary rongeurs can be used to facilitate excision. At the end of the excision, 3 to $12 \mathrm{~g}$ of muscle is considered an adequate amount of tissue. In regards to the mitral apparatus, any anomalous papillary muscles that insert directly into the body of the anterior mitral leaflet (Figure 5) may be excised, as this could help to alleviate LVOT obstruction. The aortotomy is closed in two layers and the patient is weaned off cardiopulmonary bypass.

The key principle in obtaining adequate relief of LVOT obstruction is understanding that the depth of septal excision is less important than the length of the resected portion. Residual SAM and obstruction is most often the result of failure to carry the septal myectomy far enough toward the apex (35).

\section{Current controversies}

\section{Indications}

Surgical septal myectomy is the gold standard for those 
patients with HCM who are symptomatic with a resting LVOT gradient of $\geq 30 \mathrm{mmHg}$ and refractory to maximal medical therapy. However, there is recent debate regarding the optimal management for those patients exhibiting debilitating symptoms but with a minimal LVOT gradient. Indeed, a majority of these patients will have latent, or provocable, LVOT obstruction that can manifest after physical exertion, a Valsalva maneuver, isoproterenol infusion, or administration of amyl nitrite to gradients $>50 \mathrm{mmHg}(36,37)$.

A recent study from Mayo Clinic compared outcomes after myectomy between those symptomatic patients with latent LVOT obstruction and those with high resting LVOT gradients. The investigation demonstrated that overall survival after transaortic myectomy was comparable between these two groups of patients (38). Many patients with latent obstruction will still present with symptoms identical in severity to those patients with severe resting gradients, and improvement in these symptoms to NYHA class I or II after myectomy is again comparable between the 2 groups (38). These results suggest that the underlying pathophysiology of symptoms in many patients with latent obstruction is the dynamic LVOT gradient, and that septal myectomy is indicated in those symptomatic patients just as it is in patients with fixed LVOT obstruction. Indeed, in our practice, patients with HCM and latent obstruction form approximately a third of our surgical experience with transaortic myectomy.

\section{Ablation versus myectomy}

Percutaneous transluminal septal myocardial ablation, otherwise known today as alcohol septal ablation (ASA), was introduced by Sigwart in 1994 (39) as an alternative septal reduction therapy at a time when the operative mortality from septal myectomy was much higher than it is today (up to 8\%) (40). The procedure is minimally invasive and is performed via the same approach as cardiac catheterization and coronary angiography, with injection of ethanol into the first or second septal perforator of the left anterior descending artery. Ethanol induces an iatrogenic myocardial infarction in the distribution of the basal septum and results in long-term remodeling to abolish obstruction of the LVOT.

Since its introduction, ASA has become an increasingly popular option for septal reduction therapy, such that the number of ablations performed in the last decade exceeds the number of myectomies done in the last half century (40). The minimally invasive approach may be favored by patients, despite a reported operative mortality of $<1 \%$ for surgical septal myectomy in experienced centers such as ours; the national rate of mortality is higher, reported at $5.9 \%$ in a recent study using the Nationwide Inpatient Sample (41).

There will likely never be a randomized controlled trial directly comparing ASA and myectomy due to limitations in screening and statistical power as denoted in Olivotto et al. (42). Nonetheless, there are a number of remaining concerns regarding ASA. The anatomy of the septal perforators is variable, and to a certain extent, the morphology of the hypertrophied septum can be heterogenous as well. Therefore, ASA may lead to inadequate remodeling that results in higher residual gradients as compared to surgical myectomy $(43,44)$. Furthermore, despite several case reports depicting successful treatment of midventricular obstruction (45-47), it remains uncertain whether ASA can reliably account for the complex anatomy involving the papillary muscles that is characteristic of pure midventricular obstruction in HCM (48). In regards to the mitral valve apparatus, ASA does not allow for additional intervention, such as in those instances where there is concurrent intrinsic mitral valve disease or a congenital anomaly (49).

There has been concern regarding the arrhythmogenic potential due to the iatrogenic infarction that encompasses approximately $10 \%$ of the left ventricular mass following ASA $(43,50)$. Reports of intraprocedural and postprocedural rates of complete heart block have been as high as $20 \%$, with $10 \%$ eventually needing a permanent pacemaker implantation $(48,51,52)$. The rate of sustained ventricular arrhythmias has been reported to be $1 \%$ to $3 \%$ in the early postprocedural period at experienced centers $(51,53,54)$.

Studies on long-term outcomes for ASA have been initiated in recent years, but the literature on the topic remains sparse. Sorajja et al. reported comparable survival between ASA and surgical myectomy, without an increased risk of sudden death; however, the reintervention rate for ASA was significantly higher (43). Similar results were reported by Liebregts et al. in a recent meta-analysis as well as other single-center studies $(55,56)$. Conversely, Cate $e t$ al. reported a five-fold increase in the incidence of cardiac death and arrhythmic complications after ASA as compared to myectomy (50), and Vriesendorp et al. still reported a slight increase in sudden cardiac death after ASA when compared to myectomy (57). Longer followup intervals need to be studied in order to definitively elicit any differences in efficacy and safety between ASA and 
myectomy. In the meantime, surgical myectomy should remain the gold standard for septal reduction therapy.

\section{Management of associated mitral regurgitation}

Current national and international practice still commonly involves concomitant mitral valve intervention to manage MR associated with HCM (58-62). However, in our experience, a mitral valve procedure is generally the exception rather than the norm in HCM. In most cases, the mitral valve regurgitation observed in HCM is solely due to SAM of the leaflets and apparatus. In these patients, we have found that LVOT obstruction, SAM, and the associated MR are adequately relieved with extended septal myectomy alone, such that a direct mitral valve procedure is not needed in those with purely SAM-mediated MR (63). However, if intrinsic mitral valve disease does exist-such as significant prolapse or chordal rupture-then a mitral valve procedure is warranted. In these instances, a mitral valve repair is preferred over a replacement whenever possible, due to recent studies demonstrating improved survival with the former in the HCM population $(63,64)$. Other institutions, including the group at Toronto General Hospital, have come to the same conclusion (65).

A safe and effective approach to intraoperative management of associated MR is to first perform adequate extended septal myectomy, discontinue cardiopulmonary bypass, and then re-evaluate the mitral valve apparatus with intraoperative transesophageal echocardiography to assess the need, if any exists, for an additional concomitant mitral valve procedure. If necessary, this can be done with an additional period of cardiopulmonary bypass. It has been shown that there is no difference in late survival between those patients who undergo a single cardiopulmonary bypass period versus those who undergo multiple bypass periods for myectomy (63).

\section{Surgical approach}

In some instances, the patient will present with obstruction solely in the midventricle, at or below the level of the papillary muscles. In addition, there are those patients who present with a non-obstructive apical form of HCM, which may result in a small left ventricular cavity and diastolic dysfunction due to cavitary obliteration. In these patients, a transapical approach is preferred $(38,66,67)$. After institution of cardiopulmonary bypass and cardioplegic arrest, the apex of the heart is elevated with a moist laparotomy

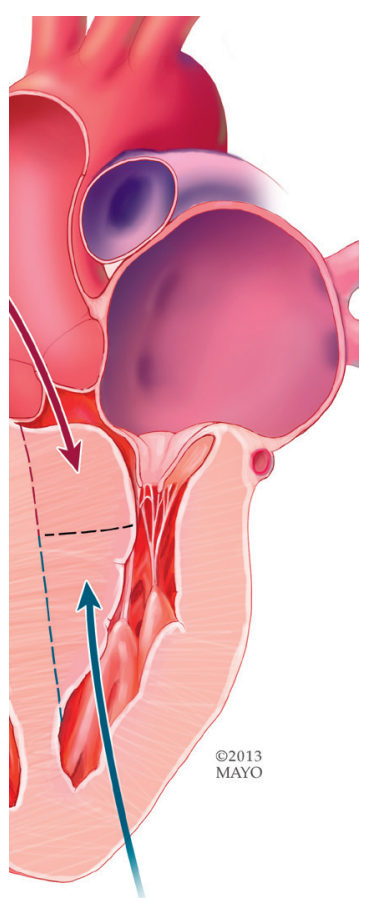

Figure 6 Long segment septal hypertrophy involving both the subaortic and midventricular regions (Copyrighted and used with permission of Mayo Foundation for Medical Education and Research).

pad positioned behind the left ventricle. An apical ventriculotomy measuring approximately 5 to $6 \mathrm{~cm}$ is made at the apical dimple, parallel and lateral to the left anterior descending coronary artery. The site of midventricular obstruction is identified by a white fibrous endocardial scar. Both papillary muscles and chordae are retracted away from the septum using the cardiotomy sucker. The hypertrophied septum and overlying endocardial scar are excised, and significantly enlarged papillary muscles as well as excess muscle on the ventricular free wall can be shaved to further relieve obstruction. Of note, in apical HCM, the papillary muscles are often displaced apically, and particular care in avoiding injury to the mitral apparatus during entry into the ventricle is warranted.

In patients with both subaortic and midventricular obstruction, or complex long-segment septal hypertrophy (Figure 6), residual midventricular obstruction may persist postoperatively if inadequate resection was done through a transaortic approach alone. To prevent residual obstruction in these patients, we combine the aforementioned techniques (i.e., both transaortic and transapical septal myectomy) at the time of their initial operation. This 
method has been used for the last 15 years at the Mayo Clinic, and the combined approach has proven to be an effective and safe approach for those patients with complex subaortic and midventricular obstruction. In addition, this approach allows for augmentation of a small left ventricular cavity in patients with diastolic heart failure with cavitary obliteration due to muscle hypertrophy.

Some surgeons advocate a minimally invasive approach to septal myectomy. Mazine and colleagues describe transaortic myectomy via a right anterior parasternal mini-thoracotomy (68). By definition, this technique would preclude the surgeon from addressing isolated midventricular obstruction or the apical variant of HCM. In addition, optimal exposure of the distal septum requires extracardiac maneuvers (such as depressing the right ventricle with a sponge-stick to expose the distal septum) which are not possible via this approach. Khalpey et al. and Kim et al. each report a case of robot-assisted septal myectomy via a transatrial, transmitral approach $(69,70)$. This method requires detachment of the anterior mitral leaflet, regardless of the presence of valve pathology, followed by reapproximation of the leaflet after septal myectomy. Unnecessary intervention on the mitral valve carries its own unforeseeable risks, and this approach again makes intervention on more distal obstruction less efficient. A transatrial, transmitral approach may be appropriate in a highly selective subgroup of patients, such as that described by Gilmanov et al., where the approach was used in those HCM patients with degenerative mitral valve disease that required repair/replacement in addition to septal myectomy (71). We have reserved the transatrial approach for small children in whom narrow aortic annuli make subaortic resection difficult or impossible.

\section{Conclusions}

There has been tremendous progress during the last half century in the understanding of HCM and its surgical treatment. Operative techniques have evolved from simple myotomy or excision of limited muscle at the point of maximal hypertrophy to the current method of extended septal myectomy, which is applicable to virtually all adult patients with HCM and subaortic obstruction. Indeed, surgical treatment of HCM has become the gold standard of therapy with mortality $<1 \%$ and symptom relief in over $90 \%$ of patients. Surgical methods are continuing to evolve, as evidenced by the development of the combined approach for complex long-segment septal hypertrophy as well as minimally invasive approaches.

\section{Acknowledgements}

This work was supported by the Paul and Ruby Tsai Family.

\section{Footnote}

Conflicts of Interest: The authors have no conflicts of interest to declare.

\section{References}

1. Maron BJ, Epstein SE. Hypertrophic cardiomyopathy: a discussion of nomenclature. Am J Cardiol 1979;43:1242-4.

2. Goodwin JF, Hollman A, Cleland WP, et al. Obstructive cardiomyopathy simulating aortic stenosis. Br Heart J 1960;22:403-14.

3. Maron MS, Olivotto I, Betocchi S, et al. Effect of left ventricular outflow tract obstruction on clinical outcome in hypertrophic cardiomyopathy. $\mathrm{N}$ Engl J Med 2003;348:295-303.

4. American College of Cardiology Foundation/American Heart Association Task Force on Practice.; American Association for Thoracic Surgery.; American Society of Echocardiography.; American Society of Nuclear Cardiology.; Heart Failure Society of America.; Heart Rhythm Society.; Society for Cardiovascular Angiography and Interventions.; Society of Thoracic Surgeons., Gersh BJ, Maron BJ, et al. 2011 ACCF/AHA guideline for the diagnosis and treatment of hypertrophic cardiomyopathy: a report of the American College of Cardiology Foundation/ American Heart Association Task Force on Practice Guidelines. J Thorac Cardiovasc Surg 2011;142:e153-203.

5. Authors/Task Force members., Elliott PM, Anastasakis A, et al. 2014 ESC Guidelines on diagnosis and management of hypertrophic cardiomyopathy: the Task Force for the Diagnosis and Management of Hypertrophic Cardiomyopathy of the European Society of Cardiology (ESC). Eur Heart J 2014;35:2733-79.

6. BROCK R. Functional obstruction of the left ventricle; acquired aortic subvalvar stenosis. Guys Hosp Rep 1957;106:221-38.

7. Teare D. Asymmetrical hypertrophy of the heart in young adults. Br Heart J 1958;20:1-8.

8. Morrow AG, Lambrew CT, Braunwald E. Idiopathic hypertrophic subaortic stenosis. II. Operative treatment 
and the results of pre- and postoperative hemodynamic evaluations. Circulation 1964;30:Suppl 4:120-51.

9. Cleland WP. The surgical management of obstructive cardiomyopathy. J Cardiovasc Surg (Torino) 1963;4:489-91.

10. Kirklin JW, Ellis FH Jr. Surgical relief of diffuse subvalvular aortic stenosis. Circulation 1961;24:739-42.

11. Frye RL, Kincaid OW, Swan HJ, et al. Results of surgical treatment of patients with diffuse subvalvular aortic stenosis. Circulation 1965;32:52-7.

12. Morrow AG, Brockenbrough EC. Surgical treatment of idiopathic hypertrophic subaortic stenosis: technic and hemodynamic results of subaortic ventriculomyotomy. Ann Surg 1961;154:181-9.

13. Heller E. Extramukose cardioplastik bein chronischen Cardiospasmus mit Dilatation des Oesophagus. Mitt Grenzgeb Med Chir 1913;27:141.

14. Wigle ED, Chrysohou A, Bigelow WG. Results of ventriculomyotomy in muscular subaortic stenosis. Am J Cardiol 1963;11:572-86.

15. Bigelow WG, Trimble AS, Auger P, et al. The ventriculomyotomy operation for muscular subaortic stenosis. A reappraisal. J Thorac Cardiovasc Surg 1966;52:514-24.

16. Trimble AS, Bigelow WG, Wigle ED, et al. Simple and effective surgical approach to muscular subaortic stenosis. Circulation 1964;29:Suppl:125-9.

17. Wigle ED, Trimble AS, Adelman AG, et al. Surgery in muscular subaortic stenosis. Prog Cardiovasc Dis 1968;11:83-112.

18. Bigelow WG, Trimble AS, Wigle ED, et al. The treatment of muscular subaortic stenosis. J Thorac Cardiovasc Surg 1974;68:384-92.

19. Morrow AG, Fogarty TJ, Hannah H 3rd, et al. Operative treatment in idiopathic hypertrophic subaortic stenosis. Techniques, and the results of preoperative and postoperative clinical and hemodynamic assessments. Circulation 1968;37:589-96.

20. Morrow AG, Reitz BA, Epstein SE, et al. Operative treatment in hypertrophic subaortic stenosis. Techniques, and the results of pre and postoperative assessments in 83 patients. Circulation 1975;52:88-102.

21. Morrow AG. Hypertrophic subaortic stenosis. Operative methods utilized to relieve left ventricular outflow obstruction. J Thorac Cardiovasc Surg 1978;76:423-30.

22. Pollick C, Morgan CD, Gilbert BW, et al. Muscular subaortic stenosis: the temporal relationship between systolic anterior motion of the anterior mitral leaflet and the pressure gradient. Circulation 1982;66:1087-94.
23. Dinsmore RE, Sanders CA, Harthorne JW. Mitral regurgitation in idiopathic hypertrophic subaortic stenosis. N Engl J Med 1966;275:1225-8.

24. Popp RL, Harrison DC. Ultrasound in the diagnosis and evaluation of therapy of idiopathic hypertrophic subaortic stenosis. Circulation 1969;40:905-14.

25. Shah PM, Gramiak R, Kramer DH. Ultrasound localization of left ventricular outflow obstruction in hypertrophic obstructive cardiomyopathy. Circulation 1969;40:3-11.

26. Simon AL, Ross J Jr, Gault JH. Angiographic anatomy of the left ventricle and mitral valve in idiopathic hypertrophic subaortic stenosis. Circulation 1967;36:852-67.

27. Adelman AG, McLoughlin MJ, Marquis Y, et al. Left ventricular cineangiographic observations in muscular subaortic stenosis. Am J Cardiol 1969;24:689-97.

28. Cooley DA, Leachman RD, Hallman GL, et al. Idiopathic hypertrophic subaortic stenosis. Surgical treatment including mitral valve replacement. Arch Surg 1971;103:606-9.

29. Krajcer Z, Leachman RD, Cooley DA, et al. Septal myotomy-myomectomy versus mitral valve replacement in hypertrophic cardiomyopathy. Ten-year follow-up in 185 patients. Circulation 1989;80:157-64.

30. Messmer BJ. Extended myectomy for hypertrophic obstructive cardiomyopathy. Ann Thorac Surg 1994;58:575-7.

31. Schoendube FA, Klues HG, Reith S, et al. Surgical correction of hypertrophic obstructive cardiomyopathy with combined myectomy, mobilisation and partial excision of the papillary muscles. Eur J Cardiothorac Surg 1994;8:603-8.

32. Wigle ED, Henderson M, Rakowski H, et al. Muscular (hypertrophic) subaortic stenosis (hypertrophic obstructive cardiomyopathy): the evidence for true obstruction to left ventricular outflow. Postgrad Med J 1986;62:531-6.

33. Schaff HV, Said SM. Transaortic Extended Septal Myectomy for Hypertrophic Cardiomyopathy. Operative Techniques in Thoracic and Cardiovascular Surgery 2012;17:238-50.

34. Ashikhmina EA, Schaff HV, Ommen SR, et al. Intraoperative direct measurement of left ventricular outflow tract gradients to guide surgical myectomy for hypertrophic cardiomyopathy. J Thorac Cardiovasc Surg 2011;142:53-9.

35. Cho YH, Quintana E, Schaff HV, et al. Residual and recurrent gradients after septal myectomy for hypertrophic cardiomyopathy-mechanisms of obstruction and outcomes 
of reoperation. J Thorac Cardiovasc Surg 2014;148:90915; discussion 915-6.

36. Vaglio JC Jr, Ommen SR, Nishimura RA, et al. Clinical characteristics and outcomes of patients with hypertrophic cardiomyopathy with latent obstruction. Am Heart J 2008;156:342-7.

37. Maron MS, Olivotto I, Zenovich AG, et al. Hypertrophic cardiomyopathy is predominantly a disease of left ventricular outflow tract obstruction. Circulation 2006;114:2232-9.

38. Schaff HV, Dearani JA, Ommen SR, et al. Expanding the indications for septal myectomy in patients with hypertrophic cardiomyopathy: results of operation in patients with latent obstruction. J Thorac Cardiovasc Surg 2012;143:303-9.

39. Sigwart U. Non-surgical myocardial reduction for hypertrophic obstructive cardiomyopathy. Lancet 1995;346:211-4.

40. Maron BJ, Nishimura RA. Surgical septal myectomy versus alcohol septal ablation: assessing the status of the controversy in 2014. Circulation 2014;130:1617-24.

41. Panaich SS, Badheka AO, Chothani A, et al. Results of ventricular septal myectomy and hypertrophic cardiomyopathy (from Nationwide Inpatient Sample [1998-2010]). Am J Cardiol 2014;114:1390-5.

42. Olivotto I, Ommen SR, Maron MS, et al. Surgical myectomy versus alcohol septal ablation for obstructive hypertrophic cardiomyopathy. Will there ever be a randomized trial? J Am Coll Cardiol 2007;50:831-4.

43. Sorajja P, Ommen SR, Holmes DR Jr, et al. Survival after alcohol septal ablation for obstructive hypertrophic cardiomyopathy. Circulation 2012;126:2374-80.

44. Ralph-Edwards A, Woo A, McCrindle BW, et al. Hypertrophic obstructive cardiomyopathy: comparison of outcomes after myectomy or alcohol ablation adjusted by propensity score. J Thorac Cardiovasc Surg 2005;129:351-8.

45. Tengiz I, Ercan E, Alioglu E, et al. Percutaneous septal ablation for left mid-ventricular obstructive hypertrophic cardiomyopathy: a case report. BMC Cardiovasc Disord 2006;6:15.

46. Seggewiss H, Faber L. Percutaneous septal ablation for hypertrophic cardiomyopathy and mid-ventricular obstruction. Eur J Echocardiogr 2000;1:277-80.

47. Angelini P, Uribe C, Monge J, et al. Apical hypertrophic cardiomyopathy: preliminary attempt at palliation with use of subselective alcohol ablation. Tex Heart Inst J 2012;39:750-5.
48. Veselka J. Twenty years of alcohol septal ablation document more than a history of a single interventional procedure. Cor Vasa 2015;57:e16-27.

49. Maron BJ, Dearani JA, Ommen SR, et al. The case for surgery in obstructive hypertrophic cardiomyopathy. J Am Coll Cardiol 2004;44:2044-53.

50. ten Cate FJ, Soliman OI, Michels M, et al. Long-term outcome of alcohol septal ablation in patients with obstructive hypertrophic cardiomyopathy: a word of caution. Circ Heart Fail 2010;3:362-9.

51. Veselka J, Lawrenz T, Stellbrink C, et al. Low incidence of procedure-related major adverse cardiac events after alcohol septal ablation for symptomatic hypertrophic obstructive cardiomyopathy. Can J Cardiol 2013;29:1415-21.

52. Veselka J, Zemánek D, Tomasov P, et al. Complications of low-dose, echo-guided alcohol septal ablation. Catheter Cardiovasc Interv 2010;75:546-50.

53. Sorajja P, Valeti U, Nishimura RA, et al. Outcome of alcohol septal ablation for obstructive hypertrophic cardiomyopathy. Circulation 2008;118:131-9.

54. Nagueh SF, Groves BM, Schwartz L, et al. Alcohol septal ablation for the treatment of hypertrophic obstructive cardiomyopathy. A multicenter North American registry. J Am Coll Cardiol 2011;58:2322-8.

55. Liebregts M, Vriesendorp PA, Mahmoodi BK, et al. A Systematic Review and Meta-Analysis of Long-Term Outcomes After Septal Reduction Therapy in Patients With Hypertrophic Cardiomyopathy. JACC Heart Fail 2015;3:896-905.

56. Steggerda RC, Damman K, Balt JC, et al. Periprocedural complications and long-term outcome after alcohol septal ablation versus surgical myectomy in hypertrophic obstructive cardiomyopathy: a single-center experience. JACC Cardiovasc Interv 2014;7:1227-34.

57. Vriesendorp PA, Liebregts M, Steggerda RC, et al. Longterm outcomes after medical and invasive treatment in patients with hypertrophic cardiomyopathy. JACC Heart Fail 2014;2:630-6.

58. Fighali S, Krajcer Z, Leachman RD. Septal myomectomy and mitral valve replacement for idiopathic hypertrophic subaortic stenosis: short- and long-term follow-up. J Am Coll Cardiol 1984;3:1127-34.

59. Desai MY, Smedira NG, Bhonsale A, et al. Symptom assessment and exercise impairment in surgical decision making in hypertrophic obstructive cardiomyopathy: Relationship to outcomes. J Thorac Cardiovasc Surg 2015;150:928-35.e1.

60. Balaram SK, Ross RE, Sherrid MV, et al. Role of mitral 
valve plication in the surgical management of hypertrophic cardiomyopathy. Ann Thorac Surg 2012;94:1990-7; discussion 1997-8.

61. Wang S, Luo M, Sun H, et al. A retrospective clinical study of transaortic extended septal myectomy for obstructive hypertrophic cardiomyopathy in China. Eur J Cardiothorac Surg 2013;43:534-40.

62. Kuć M, Kołsut P, Różański J, et al. Extended myectomy in the treatment of patients with hypertrophic obstructive cardiomyopathy. Kardiochir Torakochirurgia Pol 2016;13:300-4.

63. Hong JH, Schaff HV, Nishimura RA, et al. Mitral Regurgitation in Patients With Hypertrophic Obstructive Cardiomyopathy: Implications for Concomitant Valve Procedures. J Am Coll Cardiol 2016;68:1497-504.

64. Wan CK, Dearani JA, Sundt TM 3rd, et al. What is the best surgical treatment for obstructive hypertrophic cardiomyopathy and degenerative mitral regurgitation? Ann Thorac Surg 2009;88:727-31; discussion 731-2.

65. Weissler-Snir A, Adler A, Rakowski H. MV Surgery as Adjunct to Surgical Myectomy for Obstructive HCM: Less Is More Than Enough. J Am Coll Cardiol 2016;68:1505-8.

Cite this article as: Hang D, Nguyen A, Schaff HV. Surgical treatment for hypertrophic cardiomyopathy: a historical perspective. Ann Cardiothorac Surg 2017;6(4):318-328. doi: 10.21037/acs.2017.04.03
66. Kunkala MR, Schaff HV, Nishimura RA, et al. Transapical approach to myectomy for midventricular obstruction in hypertrophic cardiomyopathy. Ann Thorac Surg 2013;96:564-70.

67. Said SM, Schaff HV, Abel MD, et al. Transapical approach for apical myectomy and relief of midventricular obstruction in hypertrophic cardiomyopathy. J Card Surg 2012;27:443-8.

68. Mazine A, Ghoneim A, Bouhout I, et al. A Novel Minimally Invasive Approach for Surgical Septal Myectomy. Can J Cardiol 2016;32:1340-7.

69. Khalpey Z, Korovin L, Chitwood WR Jr, et al. Robotassisted septal myectomy for hypertrophic cardiomyopathy with left ventricular outflow tract obstruction. J Thorac Cardiovasc Surg 2014;147:1708-9.

70. Kim HR, Yoo JS, Lee JW. Minimally Invasive TransMitral Septal Myectomy to Treat Hypertrophic Obstructive Cardiomyopathy. Korean J Thorac Cardiovasc Surg 2015;48:419-21.

71. Gilmanov DSh, Bevilacqua S, Solinas M, et al. Minimally invasive septal myectomy for the treatment of hypertrophic obstructive cardiomyopathy and intrinsic mitral valve disease. Innovations (Phila) 2015;10:106-13. 